\title{
Detection of the Heterochirality of a 1:2 Metal/Ph-pybox Complex Ion by ESIMS
}

\author{
Hirofumi Sato, ${ }^{* 1}$ Yoshitomo Suzuki, ${ }^{2}$ Yoshio Takai, ${ }^{3}$ Hideya Kawasaki, ${ }^{2}$ Ryuichi Arakawa, ${ }^{2}$ and Motohiro Shizuma ${ }^{1}$ \\ ${ }^{1}$ Department of Biochemistry, Osaka Municipal Technical Research Institute, \\ 1-6-50 Morinomiya, Joto-ku, Osaka 536-8553 \\ ${ }^{2}$ Department of Applied Chemistry, Kansai University, Suita, Osaka 564-8680 \\ ${ }^{3}$ Material Analysis Center, The Institute of Scientific and Industrial Research, Osaka University, \\ Ibaraki, Osaka 567-0047
}

(Received March 4, 2010; CL-100203; E-mail: hsato@omtri.or.jp)

The heterochirality of a 1:2 metal/Ph-pybox complex ion was encyclopedically evaluated by ESIMS using pseudoracemic $(R, R)$ - and $(S, S)$-Ph-pybox pair, which were unlabeled/labeled by deuterium atoms, respectively. The heterochiral complex was predominantly formed in all investigated 1:2 metal/Ph-pybox complex ions.

The bis(oxazolinyl)pyridine (Sub-pybox, Sub = substituent) family of tridentate ligands were first developed by Nishiyama and co-workers for enantioselective organometallic catalysis, ${ }^{1}$ and have also been used to generate chiral Lewis acid catalysts with transition metals and lanthanides. ${ }^{2-6}$ Selective formation of crystalline diastereomeric complexes has been observed in the 1:2 metal/Ph-pybox complex $\left(\left[\mathrm{M}(\mathbf{1})_{2}\right]\right)$ as follows. Evans and Jørgensen have both observed that, even using a M:1 ratio of $1: 1$, racemic 1 gave the near insoluble, catalytically inactive complex $[\mathrm{M}(\mathbf{1 R})(\mathbf{1 S})]^{2+3,4}$ Williams has reported that heterochiral $\left[\mathrm{Co}(\text { Sub-pybox })_{2}\right]$ was formed selectively when Sub was $\mathrm{Ph}$; however, mixtures of homo- and heterochiral complexes were formed when Sub was Me and Bz. ${ }^{5}$ This diastereoselectivity was explained by the avoidance of steric interference between Ph-substituents on different ligands in the heterochiral complex and the possibility of favorable $\pi$-stacking interactions between the Ph-substituents of one pybox ligand with the pyridine ring of another pybox ligand. Aspinall found that the outcome of the reaction of $\operatorname{Ln}(\mathrm{OTf})_{3}$ with 2 equiv of racemic $\mathrm{Pr}^{i}$-pybox was dependent on the $\mathrm{Ln}^{3+}$ radius: $\mathrm{Eu}(\mathrm{OTf})_{3}$ gave exclusively the heterochiral complexes $\left[\mathrm{Eu}(\mathrm{OTf})_{3}\left(R-\mathrm{Pr}^{i}-\right.\right.$ pybox $)\left(S-\mathrm{Pr}^{i}\right.$-pybox $\left.)\right]$, whereas the use of $\mathrm{Yb}(\mathrm{OTf})_{3}$ produces an exclusively racemic mixture of homochiral complexes $\left[\mathrm{Yb}(\mathrm{OTf})_{2}\left(R-\mathrm{Pr}^{i} \text {-pybox }\right)_{2}\right]^{+}$and $\left[\mathrm{Yb}(\mathrm{OTf})_{2}\left(S-\mathrm{Pr}^{i}-\text { pybox }\right)_{2}\right]^{+}{ }^{6} \mathrm{Al}-$ though the metal dependency of the $1: 2 \mathrm{metal} / \mathrm{pybox}$ complex structure is interesting, previous structural analysis was solely dependent on crystallographic analysis. Recently, chiral mass spectrometry has been developed as a new analytical approach for stereochemistry, which has the advantages of being a rapid and simple analytical technique. ${ }^{7}$ Herein, we report the explicit index of the heterochiral complex selectivity using electro-spray ionization mass spectrometry (ESIMS).

Isotopic-labeling is a highly useful method for the discrimination of a compound from the same structural compounds using mass spectrometry. ${ }^{8}$ In the present study we used a pseudo-racemic mixture of $(R, R)$ - and $(S, S)$-Ph-pybox (1R and 1S-d, respectively) which was unlabeled/labeled with four deuterium atoms at the 5-position of oxazoline (Figure 1). ${ }^{9}$ As the labeled position is located on the outside of the tridentate nitrogen atoms, the labeling has no influence on the formation of

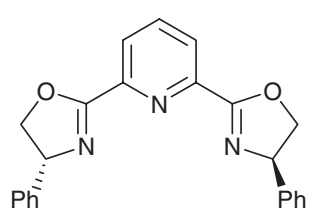

1R<smiles>[R]C1([R])OC(c2cccc(C3=N[C@@H](c4ccccc4)[C@H](P)C3([R])[2H])n2)=N[C@@H]1c1ccccc1</smiles>

1S-d $(R=D)$
Figure 1. Structure of the Ph-pybox showing the labeling with and without deuterium atoms (1R, 1S, and 1S-d, respectively).

complexes. 1S-d was synthesized from pyridine-2,6-dicarbonyl chloride and $(S)$-phenylglycinol- $d_{2}$, which was obtained from the $(S)$-phenylglycine methyl ester by reduction using $\mathrm{NaBD}_{4}$ in THF. ${ }^{7,10}$ The deuteration rate of $71 \%$ was determined by comparing the isotopic pattern with the theoretical pattern (Figure S1). ${ }^{10}$

The sample was prepared by mixing 1R, 1S-d, and metal nitrate at concentrations of 10,10 , and $20 \mu \mathrm{M}$ in $10 \%$ methanol in acetonitrile, respectively. The mixture was capped and left undisturbed in a plastic bottle at room temperature for $24 \mathrm{~h}$.

The ESIMS experiments were conducted on a ThermoQuest $\mathrm{LCQ}^{\mathrm{DECA}}$ with an ion trap instrument. The following instrument and analytical conditions were used: spray voltage, $5 \mathrm{kV}$; spray current, $0.10 \mu \mathrm{A}$; sheath gas flow rate, 29.2 units (roughly $0.78 \mathrm{~L} \mathrm{~min}^{-1}$ ); capillary voltage, $35.2 \mathrm{~V}$; heated capillary temperature, $200^{\circ} \mathrm{C}$. The experiments were conducted in the positive ion mode. Spectra shown represent the average of 60 scans, with each scan requiring $0.2 \mathrm{~s}$. The sample was infused via a syringe pump at a flow rate of $3 \mu \mathrm{L} \mathrm{min}^{-1}$.

Typical mass spectra of $\mathrm{Na}$ and La systems are shown in Figure 2. In the case of the Na system, the highest mass peak at $\mathrm{m} / \mathrm{z} 765$ corresponds to the mass of the heterochiral complex ion $[\mathrm{Na}(\mathbf{1 R})(\mathbf{1 S}-\mathbf{d})]^{+}$, consisting of sodium and two Ph-pybox ligands, in which the absolute configuration is different. The inset to the figure shows the peaks around the RS-heterochiral complex ion peak (circle). RR- (triangle) and SS-homochiral (diamond) complex ion peaks were also observed four units apart from the RS-homochiral complex ion peak. The peak intensity should reflect the amount of each diastereomer when the ionization efficiencies are the same. Thus, eq 1 provides the diastereomeric excess of the heterochiral complex $\left(\mathrm{de}_{\mathrm{RS}}\right)$ in forming the 1:2 metal/Ph-pybox complex.

$$
\mathrm{de}_{\mathrm{RS}}=\left(I_{\mathrm{RS}}-I_{\mathrm{RR}}-I_{\mathrm{SS}}\right) /\left(I_{\mathrm{RS}}+I_{\mathrm{RR}}+I_{\mathrm{SS}}\right)
$$

where $\mathrm{de}_{\mathrm{RS}}$ is the diastereomeric excess of the heterochiral complex, $I_{\mathrm{RS}}$ is the intensity of the RS-heterochiral complex ion 

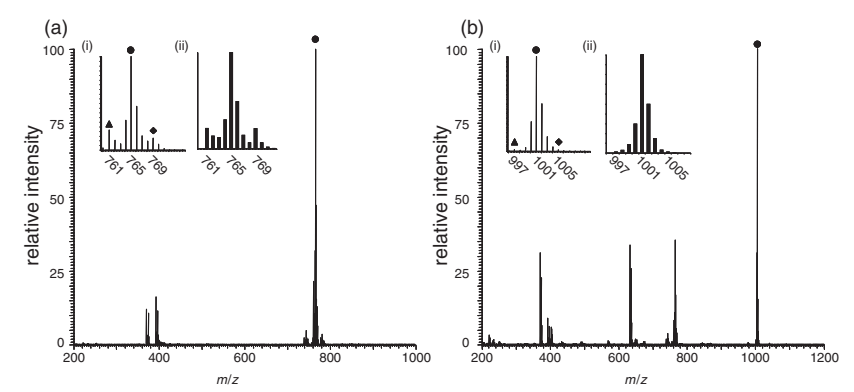

Figure 2. ESI mass spectra of (a) $\left[\mathrm{Na}(\mathbf{1})_{2}\right]^{+}$and (b) $\left[\mathrm{La}(\mathbf{1})_{2}\left(\mathrm{NO}_{3}\right)_{2}\right]^{+}$. Insets: (i) expanded view of the complex ion peak. (ii) the theoretical isotope distribution. The circle, triangle, and diamond symbols show the RS-heterochiral, RR-homochiral, and SS-homochiral complex ions, respectively.

$[m / z:(m+4) /$ charge $], I_{\mathrm{RR}}$ is the intensity of the RR-homochiral complex ion $\left[\mathrm{m} / z: \mathrm{m} /\right.$ charge], and $I_{\mathrm{SS}}$ is the intensity of the SShomochiral complex ion $[m / z:(m+8) /$ charge].

As the isotopic purity of $\mathbf{1 S - d}$ was $71 \%$, de $\mathrm{RS}_{\mathrm{RS}}$ was corrected by its natural abundance. The ratio of $I_{\mathrm{RR}}: I_{\mathrm{RS}}: I_{\mathrm{SS}}$ was $1: 4.9: 1$ and the $\mathrm{de}_{\mathrm{RS}}$ value of the $\mathrm{Na}$ system was 0.42 , indicating that the heterochiral complex ion was formed in preference to the homochiral complex ion. In the case of the La system, the highest mass peak at $m / z 1005$ corresponds to the heterochiral complex ion $\left[\mathrm{La}(\mathbf{1 R})(\mathbf{1 S}-\mathbf{d})\left(\mathrm{NO}_{3}\right)_{2}\right]^{+}$. Interestingly, the peak for the homochiral complex ion was never observed in the spectrum and the $\mathrm{de}_{\mathrm{RS}}$ value is above 0.99 , indicating that the heterochiral complex was exclusively formed in the media. Aspinall and coworkers reported that the formation of the lanthanide heterochiral or homochiral complexes was dependent on the metal radius and a heterochiral single crystal was obtained from metals with larger radii such as Eu. ${ }^{6}$ Consequently, assuming that the effect of the counter anion on complex formation is negligible, it is clear that La exclusively forms the heterochiral complex.

$\mathrm{De}_{\mathrm{RS}}$ values of all investigated metals and the metal radius for the six coordination numbers ${ }^{11}$ are summarized in Table 1 . In the case of alkali metal systems, the peak intensities of the $1: 2$ metal/Ph-pybox complexes and the de $\mathrm{RS}_{\mathrm{RS}}$ values decreased as the radius of the ions increased. Exiguous peaks were observed in the $\mathrm{Rb}$ system due to its low ionization efficiency. In the case of the transition-metal systems, single-charged $\left[\mathrm{M}(\mathbf{1})_{2}\left(\mathrm{NO}_{3}\right)\right]^{+}$ complexes were observed in all bivalent metal systems, and double-charged $\left[\mathrm{M}(\mathbf{1})_{2}\right]^{2+}$ complexes were observed for $\mathrm{Mn}, \mathrm{Co}$, $\mathrm{Cu}$, and $\mathrm{Zn}$ systems. Interestingly, single- or double-charged complexes may alternatively give exclusive de $_{R S}$ values when nitrate is included as the ligand or the counter ion. In the case of the lanthanides, $\left[\mathrm{M}(\mathbf{1})_{2}\left(\mathrm{NO}_{3}\right)_{2}\right]^{+}$was observed. High de $\mathrm{RS}$ values were observed from La to Er, and low de $\mathrm{RS}_{\mathrm{RS}}$ value was observed in Tm. These phenomena suggested that radii smaller than Tm give low $\mathrm{de}_{\mathrm{RS}}$ complexes, such as crystalline $\mathrm{Yb}$ complex reported by Aspinall. The effects on the diastereoselectivity of alkali metal systems against the metal radius were quite different from those of lanthanide systems. In the case of the alkali metals, the stable heterochiral complex formed in the smaller ion because the electrons in the outermost shell is the spherical s-type orbital and the steric interaction increases between the two Ph-pybox ligands. In the case of the lanthanide systems, the steric congestion at the smaller Tm center may have resulted in the ejection of the nitrate ligand from the coordination sphere.
Table 1. The de $\mathrm{RS}_{\mathrm{RS}}$ values of the 1:2 metal/Ph-pybox complexes

\begin{tabular}{|c|c|c|c|}
\hline Metal & Complex ion & $\mathrm{de}_{\mathrm{RS}}^{\mathrm{a}}$ & $\begin{array}{c}\text { Metal } \\
\operatorname{radius}^{11} / \AA\end{array}$ \\
\hline $\mathrm{Li}$ & {$\left[\operatorname{Li}(\mathbf{1})_{2}\right]^{+}$} & 0.71 & 0.76 \\
\hline $\mathrm{Na}$ & {$\left[\mathrm{Na}(\mathbf{1})_{2}\right]^{+}$} & 0.42 & 1.02 \\
\hline $\mathrm{K}$ & {$\left[\mathrm{K}(\mathbf{1})_{2}\right]^{+}$} & 0.00 & 1.38 \\
\hline $\mathrm{Rb}$ & {$\left[\operatorname{Rb}(\mathbf{1})_{2}\right]^{+}$} & 0.03 & 1.52 \\
\hline $\operatorname{Mn}(\mathrm{II})$ & $\begin{array}{l}{\left[\mathrm{Mn}(1)_{2}\left(\mathrm{NO}_{3}\right)\right]^{+},} \\
{\left[\mathrm{Mn}(1)_{2}\right]^{2+}}\end{array}$ & $0.57,1.00$ & 1.67 \\
\hline $\mathrm{Fe}(\mathrm{II})$ & {$\left[\mathrm{Fe}(\mathbf{1})_{2}\left(\mathrm{NO}_{3}\right)\right]^{+}$} & 0.95 & 1.92 \\
\hline $\mathrm{Co}(\mathrm{II})$ & $\begin{array}{l}{\left[\mathrm{Co}(\mathbf{1})_{2}\left(\mathrm{NO}_{3}\right)\right]^{+},} \\
{\left[\mathrm{Co}(\mathbf{1})_{2}\right]^{2+}}\end{array}$ & $0.93,1.00$ & 1.65 \\
\hline $\mathrm{Ni}(\mathrm{II})$ & {$\left[\mathrm{Ni}(\mathbf{1})_{2}\left(\mathrm{NO}_{3}\right)\right]^{+}$} & 0.68 & 1.69 \\
\hline $\mathrm{Cu}(\mathrm{II})$ & $\begin{array}{l}{\left[\mathrm{Cu}(\mathbf{1})_{2}\left(\mathrm{NO}_{3}\right)\right]^{+},} \\
{\left[\mathrm{Cu}(\mathbf{1})_{2}\right]^{2+}}\end{array}$ & $1.00,0.76$ & 1.73 \\
\hline $\mathrm{Zn}(\mathrm{II})$ & $\begin{array}{l}{\left[\mathrm{Zn}(\mathbf{1})_{2}\left(\mathrm{NO}_{3}\right)\right]^{+}} \\
{\left[\mathrm{Zn}(\mathbf{1})_{2}\right]^{2+}}\end{array}$ & $0.69,1.00$ & 1.74 \\
\hline $\mathrm{Y}(\mathrm{III})$ & {$\left[\mathrm{Y}(\mathbf{1})_{2}\left(\mathrm{NO}_{3}\right)_{2}\right]^{+}$} & 0.95 & 0.87 \\
\hline $\operatorname{Pd}(\mathrm{II})$ & {$\left[\mathrm{Pb}(\mathbf{1})_{2}\left(\mathrm{NO}_{3}\right)\right]^{+}$} & 0.95 & 1.19 \\
\hline $\operatorname{Ag}(\mathrm{I})$ & {$\left[\operatorname{Ag}(\mathbf{1})_{2}\right]^{+}$} & 0.65 & 1.15 \\
\hline $\mathrm{Cd}(\mathrm{II})$ & {$\left[\mathrm{Cd}(\mathbf{1})_{2}\left(\mathrm{NO}_{3}\right)\right]^{+}$} & 1.00 & 0.95 \\
\hline $\mathrm{La}(\mathrm{III})$ & {$\left[\mathrm{La}(\mathbf{1})_{2}\left(\mathrm{NO}_{3}\right)_{2}\right]^{+}$} & 0.98 & 1.03 \\
\hline $\mathrm{Ce}(\mathrm{III})$ & {$\left[\mathrm{Ce}(\mathbf{1})_{2}\left(\mathrm{NO}_{3}\right)_{2}\right]^{+}$} & 0.97 & 1.01 \\
\hline $\mathrm{Nd}(\mathrm{III})$ & {$\left[\mathrm{Nd}(\mathbf{1})_{2}\left(\mathrm{NO}_{3}\right)_{2}\right]^{+}$} & 0.91 & 0.98 \\
\hline $\mathrm{Tb}(\mathrm{III})$ & {$\left[\mathrm{Tb}(\mathbf{1})_{2}\left(\mathrm{NO}_{3}\right)_{2}\right]^{+}$} & 0.99 & 0.92 \\
\hline Ho(III) & {$\left[\mathrm{Ho}(\mathbf{1})_{2}\left(\mathrm{NO}_{3}\right)_{2}\right]^{+}$} & 0.91 & 0.90 \\
\hline $\operatorname{Er}(\mathrm{III})$ & {$\left[\operatorname{Er}(\mathbf{1})_{2}\left(\mathrm{NO}_{3}\right)_{2}\right]^{+}$} & 0.92 & 0.89 \\
\hline $\operatorname{Tm}(\mathrm{III})$ & {$\left[\operatorname{Tm}(\mathbf{1})_{2}\left(\mathrm{NO}_{3}\right)_{2}\right]^{+}$} & 0.58 & 0.88 \\
\hline
\end{tabular}

${ }^{\mathrm{a}} \mathrm{de}_{\mathrm{RS}}=\left(I_{\mathrm{RS}}-I_{\mathrm{RR}}-I_{\mathrm{SS}}\right) /\left(I_{\mathrm{RS}}+I_{\mathrm{RR}}+I_{\mathrm{SS}}\right)$, where $I_{\mathrm{RS}}, I_{\mathrm{RR}}$, and $I_{\mathrm{SS}}$ are relative intensity of heterochiral and homochiral complexes, respectively.

In summary, we have described an excellent heterochirality determination ESIMS method for 1:2 metal/Ph-pybox complexes using pseudo-racemic Ph-pybox unlabeled/labeled with deuterium atoms. More than 20 metal ions were encyclopedically investigated by this method and the heterochirality of the complexes with transition metals and lanthanides was positive, indicating that $\mathrm{Ph}$-pybox inherently forms heterochiral complexes.

\section{References and Notes}

1 a) H. Nishiyama, M. Kondo, T. Nakamura, K. Itoh, Organometallics 1991, 10, 500. b) Y. Motoyama, O. Kurihara, K. Murata, K. Aoki, H. Nishiyama, Organometallics 2000, 19, 1025.

2 For $\mathrm{Cu}$ : a) D. M. Black, R. Davis, B. D. Doan, T. C. Lovelace, A. Millar, J. F. Toczko, S. Xie, Tetrahedron: Asymmetry 2008, 19, 2015. b) O. Baslé, C.-J. Li, Org. Lett. 2008, 10, 3661. For Ru: c) M. K. Tse, S. Bhor, M. Klawonn, G. Anilkumar, H. Jiao, C. Döbler, A. Spannenberg, W. Mägerlein, H. Hugl, M. Beller, Chem.-Eur. J. 2006, 12, 1855. d) E. Milczek, N. Boudet, S. Blakey, Angew. Chem., Int. Ed. 2008, 47, 6825. For Pd: e) A. B. Kazi, G. D. Jones, D. A. Vicic, Organometallics 2005, 24, 6051. f) $\mathrm{T}$. Kusakabe, K. Kato, S. Takaishi, S. Yamamura, T. Mochida, H. Akita, T. A. Peganova, N. V. Vologdin, O. V. 
Gusev, Tetrahedron 2008, 64, 319. For Ag: g) C. Provent, S. Hewage, G. Brand, L. J. Charbonnière, A. F. Williams, G. Bernardinelli, Angew. Chem., Int. Ed. Engl. 1997, 36, 1287. For Ni: h) V. B. Phapale, E. Buñuel, M. García-Iglesias, D. J. Cárdenas, Angew. Chem., Int. Ed. 2007, 46, 8790. For Sc: i) T. E. Reynolds, M. S. Binkley, K. A. Scheidt, Org. Lett. 2008, 10, 2449. For lanthanides: j) G. Desimoni, G. Faita, M. Guala, C. Pratelli, J. Org. Chem. 2003, 68, 7862. k) H. Suga, T. Suzuki, K. Inoue, A. Kakehi, Tetrahedron 2006, 62, 9218. 1) S. E. Schaus, E. N. Jacobsen, Org. Lett. 2000, 2, 1001. m) H. Yamamoto, S. Hayashi, M. Kubo, M. Harada, M. Hasegawa, M. Noguchi, M. Sumimoto, K. Hori, Eur. J. Org. Chem. 2007, 2859.

3 D. A. Evans, M. C. Kozlowski, J. A. Murry, C. S. Burgey, K. R. Campos, B. T. Connell, R. J. Staples, J. Am. Chem. Soc. 1999, 121, 669.

4 S. Saaby, K. Nakama, M. A. Lie, R. G. Hazell, K. A. Jørgensen, Chem.-Eur. J. 2003, 9, 6145.

5 C. Provent, G. Bernardinelli, A. F. Williams, N. Vulliermet, Eur. J. Inorg. Chem. 2001, 1963.

6 H. C. Aspinall, J. F. Bickley, N. Greeves, R. V. Kelly, P. M. Smith, Organometallics 2005, 24, 3458.
7 a) M. Speranza, Int. J. Mass Spectrom. 2004, 232, 277. b) A. Filippi, A. Giardini, S. Piccirillo, M. Speranza, Int. J. Mass Spectrom. 2000, 198, 137. c) M. Sawada, Mass Spectrom. Rev. 1997, 16, 73. d) W. A. Tao, R. G. Cooks, Anal. Chem. 2003, 75, 25A.

8 a) M. Sawada, Y. Takai, H. Yamada, H. Yamaoka, T. Azuma, T. Fujioka, Y. Kawai, T. Tanaka, Chem. Commun. 1998, 1569. b) M. Shizuma, H. Imamura, Y. Takai, H. Yamada, T. Takeda, S. Takahashi, M. Sawada, Chem. Lett. 2000, 1292. c) M. Shizuma, Y. Kadoya, Y. Takai, H. Imamura, H. Yamada, T. Takeda, R. Arakawa, S. Takahashi, M. Sawada, J. Org. Chem. 2002, 67, 4795. d) M. Sawada, Y. Takai, H. Yamada, S. Hirayama, T. Kaneda, T. Tanaka, K. Kamada, T. Mizooku, S. Takeuchi, K. Ueno, K. Hirose, Y. Tobe, K. Naemura, J. Am. Chem. Soc. 1995, 117, 7726.

9 Y. Takai, K. Iguchi, H. Yamada, M. Shizuma, R. Arakawa, M. Sawada, J. Mass Spectrom. 2006, 41, 266.

10 Supporting Information is available electronically on the CSJ-Journal Web site, http://www.csj.jp/journals/chem-lett/ index.html.

11 R. D. Shannon, Acta Crystallogr., Sect. A 1976, 32, 751. 